\title{
Four Point Bending: A New Look
}

\author{
William K. Szaroletta, Nancy L. Denton \\ Purdue University, West Lafayette, Indiana
}

\begin{abstract}
:
Four point bending (FPB) is a cornerstone element of the beam flexure portion of a sophomorelevel mechanics of materials course. The FPB lecture has traditionally developed the theory from free body diagram through beam deflection, with related homework problems providing analytical practice. Similarly, the FPB laboratory, which has been essentially unchanged for nearly two decades, has provided students an opportunity to experimentally and analytically verify and validate beam flexure theory. Although excellent correlation between theoretical and experimental results was frequently obtained, hardware requirements have limited the accuracy and amount of data that collected within a standard 110-minute laboratory session.
\end{abstract}

Recent FPB laboratory upgrades utilizing data acquisition (DAQ) hardware and software have enabled the students to test a much larger sample of beams in roughly the same timeframe with increased repeatability. The DAQ upgrade has facilitated increased understanding of flexural theory, introduced modern experimental methods in both lecture and laboratory, given students a more robust data set upon which to base their analyses, and enhanced student experiences with technical report writing. This paper includes an overview of FPB theory, analysis techniques, and traditional laboratory procedures, and details the success of the FPB DAQ upgrade, operation, and outputs.

\section{Introduction:}

Beam flexure represents one of the three most common loading categories for mechanical systems. As such, it is on the syllabi of nearly all sophomore-level mechanics of materials courses, including the mechanical engineering technology course under consideration here. Within the lecture setting, FPB theory is developed from free-body diagram through beam deflection. Theory is reinforced by analytical practice solving related homework problems ${ }^{1-3}$. The corresponding FPB laboratory has afforded students the opportunity to experimentally and analytically verify and validate beam flexure theory ${ }^{3}$. Excellent correlation between theoretical and experimental results is often obtained. However, the person-centered, primarily analog method used for acquiring, recording, and analyzing the data is cumbersome and frustrating for the students. The accuracy and amount of data that can be collected within a standard 110-minute laboratory session has been limited, as has the extent of the analysis that seems reasonable to require.

To address student dissatisfaction with the FPB laboratory, a revision was deemed desirable. The implemented revision was designed to accommodate faculty concerns that the students have a laboratory experience that mirrors the industrial laboratory and obtain additional practice manipulating experimental data. Thus, the FPB laboratory has recently been upgraded through the inclusion of automated data acquisition (DAQ) hardware and software. This upgrade has 
facilitated increased understanding of flexural theory, introduced modern experimental methods in both lecture and laboratory, given students a more robust data set upon which to base their analyses, and enhanced student experiences with technical report writing. The following paragraphs provide an overview of FPB theory, analysis techniques, the basic laboratory procedure, and details of the upgraded FPB experiment.

\section{Theoretical Basis for the FPB Experiment:}

Following the testing conventions specified in ASTM D6272-00 transverse vertical loads are applied to horizontal beams such that a constant bending moment results between the two inner load locations ${ }^{4}$. Figure 1 shows the corresponding loading diagrams, from free-body to bending moment.

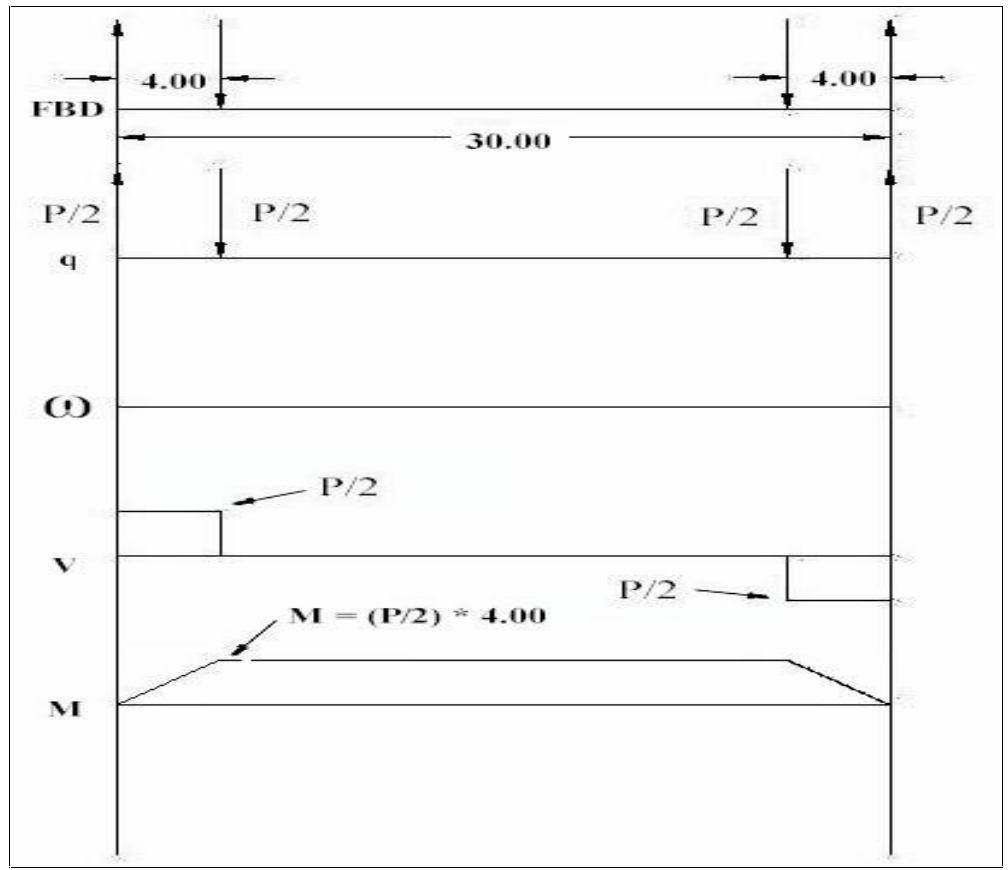

\section{Figure 1: Example of Free Body, Instantaneous Load, Distributed Load, Shear, and Moment diagrams for the laboratory experiment on four point bending.}

Stress-strain relationships are utilized to develop the theoretical parametric relationship between strain, $\varepsilon$, bending moment, $\mathrm{M}$, tensile modulus, E, width, $\mathrm{b}$ and height, $\mathrm{h}$. The relationship between these parameters is depicted below in equation 1 below:

$$
\varepsilon=6 \mathrm{M} /\left(\mathrm{Ebh}^{2}\right)
$$

In addition to maintaining a constant bending moment over much of the span of the beams, variation in the modulus of elasticity and width is minimized by cutting each set of test beams from a single piece of aluminum plate stock. The relationship between flexural stress and strain can then be reduced to the form depicted in equation 2 , where $\mathrm{C}$ denotes a constant that is based on a single applied load at the load cell ${ }^{1}$ :

$$
\varepsilon=\mathrm{C} * \mathrm{~h}^{-2}
$$

Figure 2 below depicts the components of the FPB test fixture. 


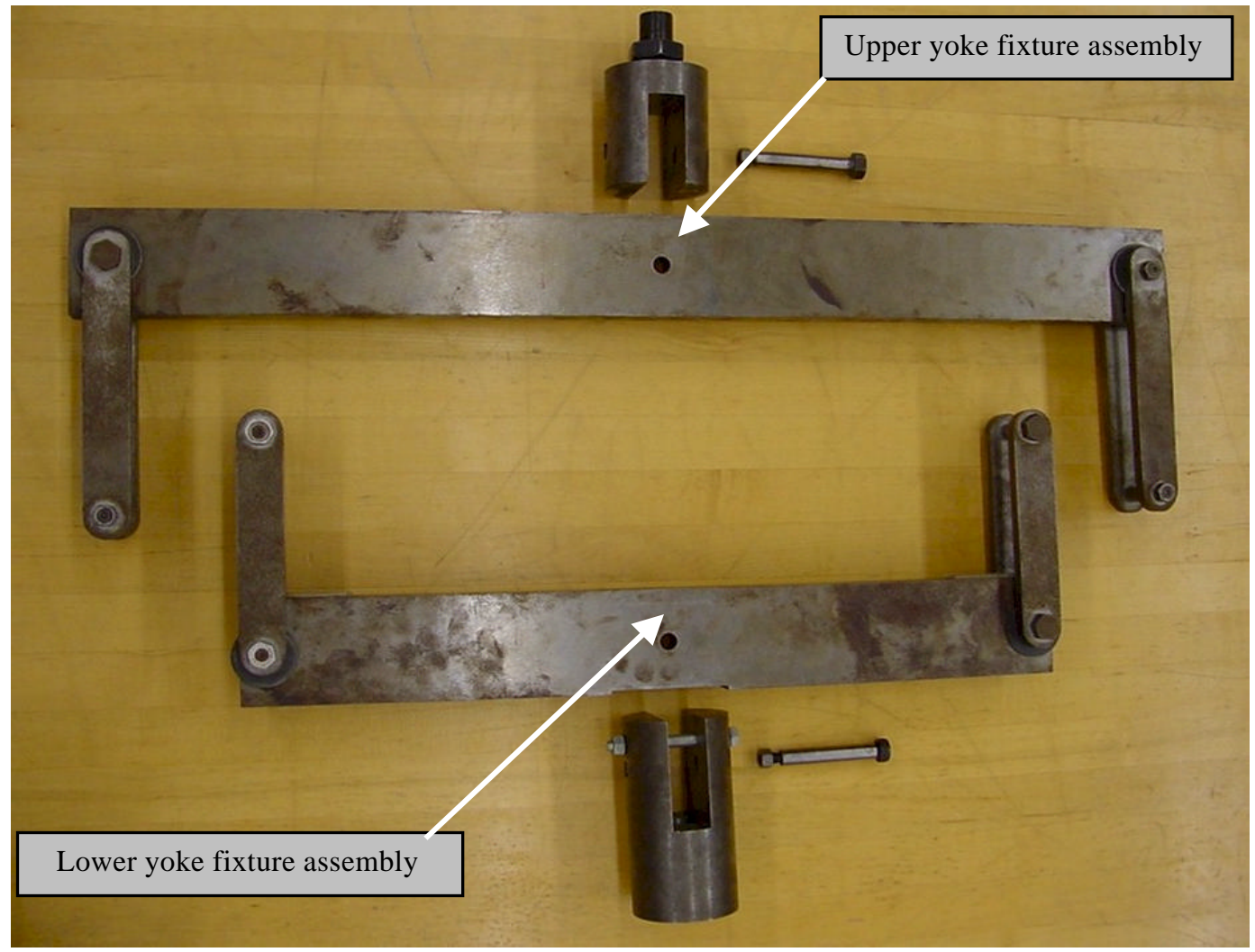

Figure 2: Components of the traditional four point bending fixture also used in upgrade

\section{FBP Experiment Fundamentals:}

The FPB laboratory, which has been essentially unchanged for nearly two decades, has provided students an opportunity to experimentally and analytically verify and validate beam flexure theory. Each set of test beams consists of five rectangular cross-section aluminum beams of equal width (1.0 in), at heights ranging from 1.5 " to 3.5 ", as shown in figure 3.

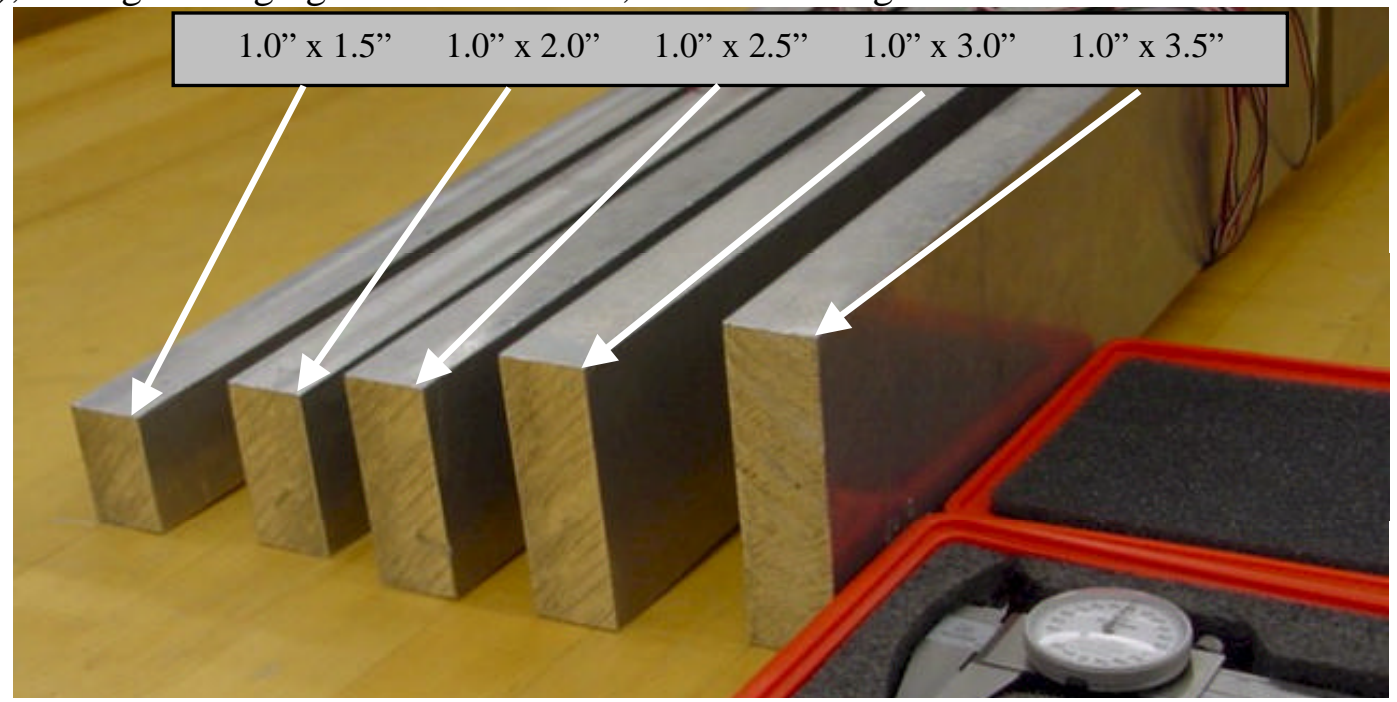

Figure 3: Four point bending utilizes five 6061-T6 beams per station

Each beam is instrumented with two strain gages along the longitudinal axis, one on top and one on bottom. Given the rectangular cross-section of the beams, the strain on the top, compressive 
and bottom, tensile sides of the beam will be equal in magnitude, but opposite in sign as long as only bending is present. The two strain gages were wired into a half-bridge Wheatstone bridge arrangement to increase strain measurement sensitivity because doubling the gage factor essentially doubles the voltage input to the instrumentation, in this case a single Vishay Measurement Group's P3500 Strain Indicator for the half bridge arrangement ${ }^{6}$. The half-bridge circuit arrangement that was utilized is depicted below in Figure 4 from the Vishay Measurement Group's website ${ }^{6}$. This subtraction-type strain gage configuration removes most axial and torsional strain effects, if any are unintentionally present in the beam during testing.
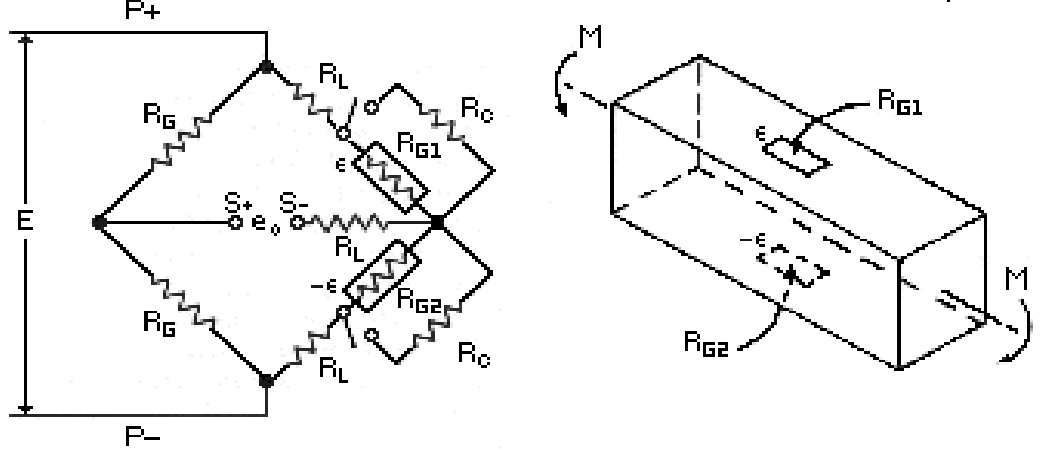

\section{Figure 4: Half bridge Wheatstone bridge circuit and beam flexure application}

The fixture that loads the above beams in four point bending consists primarily of custom-design and fabricated elements loaded into a standard universal testing machine (UTM). The upper yoke fixture elements are designed to provide vertical tensile loads spaced thirty inches (30") apart. These loads are each half of the tensile load measured at the load cell. The stationary, lower yoke fixture elements are designed to provide reactions to the applied tensile loads at points spaced towards the beam center by four inches (4"). The beam specimens are tested with the fixture mounted in a universal testing machine (UTM) as shown in Figure 5 below, which shows testing in progress.

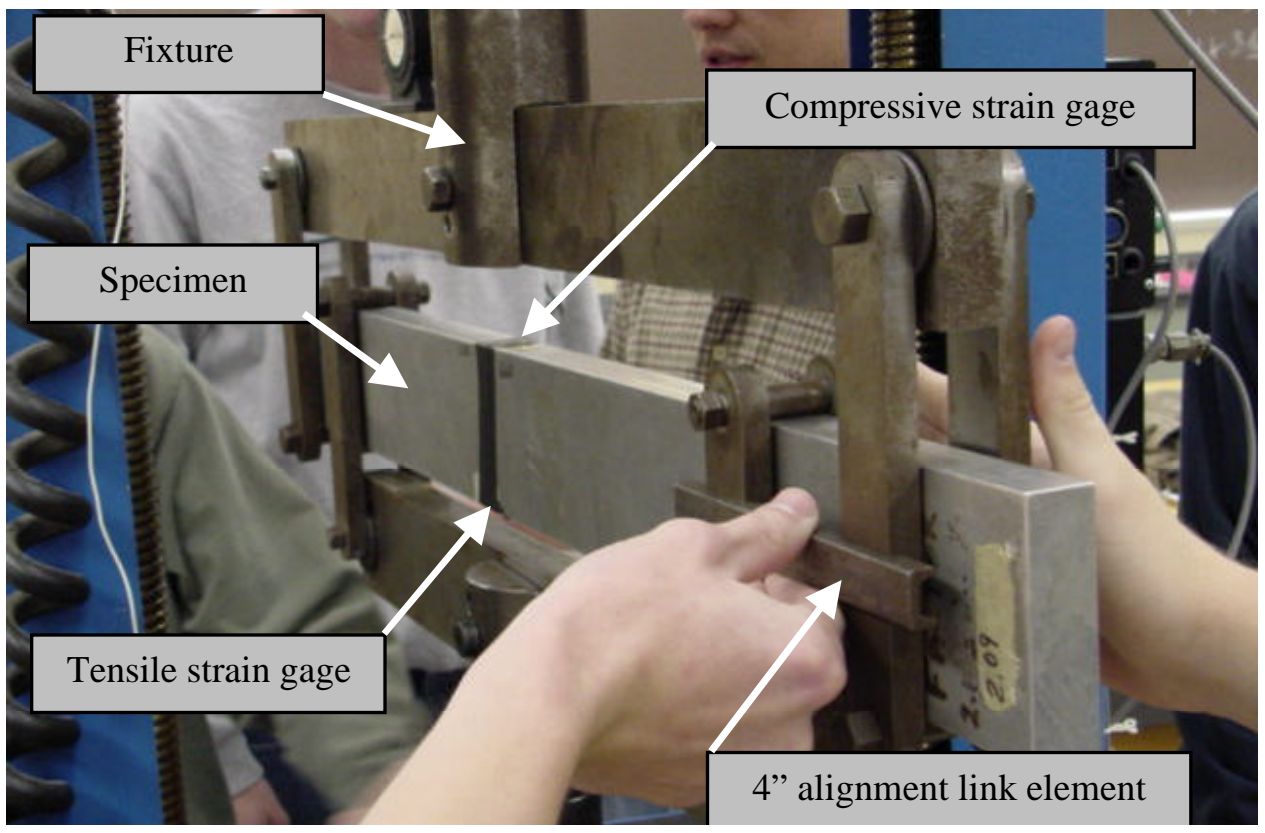

Figure 5: Four point bending experimental setup with 1.0" $x$ 3.5" specimen being inserted. The link elements allow the specimen to be loaded in uniform bending. 


\section{Historical data acquisition and analysis:}

For several decades, data for the FPB laboratory has been acquired by transmitting voltage signals from two strain indicators to an X-Y Recorder. The load signal was plotted as "Y", while the strain signal was plotted as " $\mathrm{X}$ ". Each beam was loaded by raising the upper portion of the test fixture (at the same rate for all beams). Rewiring and re-calibration of the strain indicators occurred following the testing of each beam.

For all five beams, load versus strain data points were plotted on a single graph. The graph was photocopied to share data among group members. Analysis was limited to consideration of theory and data at one load on each of the beams, with a typical load specified between $1000 \mathrm{lb}_{\mathrm{f}}$ and $1500 \mathrm{lb}_{\mathrm{f}}$. Theoretical strain values were calculated and graphically compared to the measured strains at the same load. A log-log graph of measured strain at the specified load versus beam height was then generated, including the exponential equation resulting from a power regression. Early versions of the graphs were hand-generated, then later, produced using spreadsheet software.

The experimentally derived equation describing measured strain versus beam height corresponds to the theoretical equation listed previously as equation $2, \varepsilon=\mathrm{Ch}^{-2}$, where $\mathrm{C}$ represents the yintercept and -2 is the slope on a log-log graph of strain versus beam height. The theoretical and experimental slopes and y-intercepts were compared, with differences often on the order of $10 \%$ or less deviation from theory.

In order to help the students recognize that they have reached the laboratory objectives of correlating experiment with theory, understanding the relationship between geometric stiffness and stress/strain, and gaining familiarity with standard testing procedures, they were asked to answer several questions in their laboratory write-up:

1) How well do strain gage results agree with theory?

2) How does beam height affect strain and stress?

3) What ASTM four point bending procedures were followed in this lab? ${ }^{3}$

Problems inherent to the FPB experiment's historical data acquisition and analysis were minor but numerous. Examples include signal noise in the X-Y recorders, shifting of the graph paper between test runs, data distortion through photocopying, low resolution when reading data from the graph (from pen width and scaling), and the opportunity for human error in the reading and transcription of all data values. When these error sources were coupled with changes in typical industrial laboratory practice, the need for upgrading became compelling. 
Four Point Bending Upgrades, Operation, and Outputs:

The traditional FPB laboratory was upgraded using data acquisition (DAQ) hardware and software, specifically National Instruments' LabVIEW ${ }^{\mathrm{TM}}{ }^{5}$. Figure 6 depicts both the traditional and upgraded FPB laboratories for comparison.

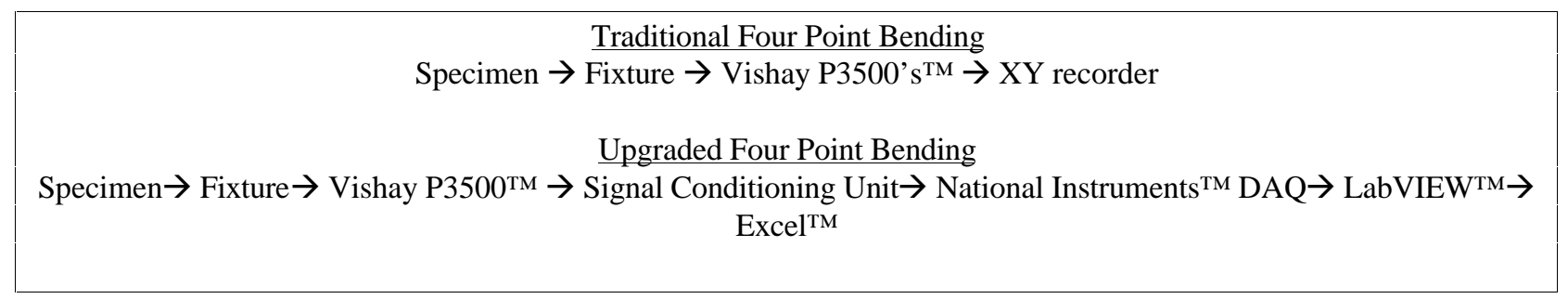

\section{Figure 6: Block comparison of traditional and upgraded FPB laboratories}

This DAQ setup has resulted in observed improvements in laboratory group efficiency. These improvements have enabled roughly twice the number of experimental runs to be accomplished in the same time period, giving a more extensive pool of raw data to support subsequent student analysis.

To support the DAQ, the important concept of multiple calibration is developed during a prior lecture period. Multiple calibration requires students to first calibrate a transducer with respect to the Wheatstone bridge unit, in this case a VMG P3500 ${ }^{\mathrm{TM}}$, and then calibrate the output of the $\mathrm{P} 3500^{\mathrm{TM}}$ with respect to the DAQ signal conditioning unit. In the first calibration step, the transducer gage factor and required Wheatstone bridge arrangement must properly be input to the strain gage P3500 ${ }^{\mathrm{TM}}$. The transducer gage factor is the sum of the individual gage factors of the two strain gages for this half-bridge arrangement. The load cell's gage factor is input to the second $\mathrm{P} 3500^{\mathrm{TM}}$. This Transducer $\rightarrow \mathrm{P} 3500^{\mathrm{TM}}$ calibration step is shown below in Figure 7 .

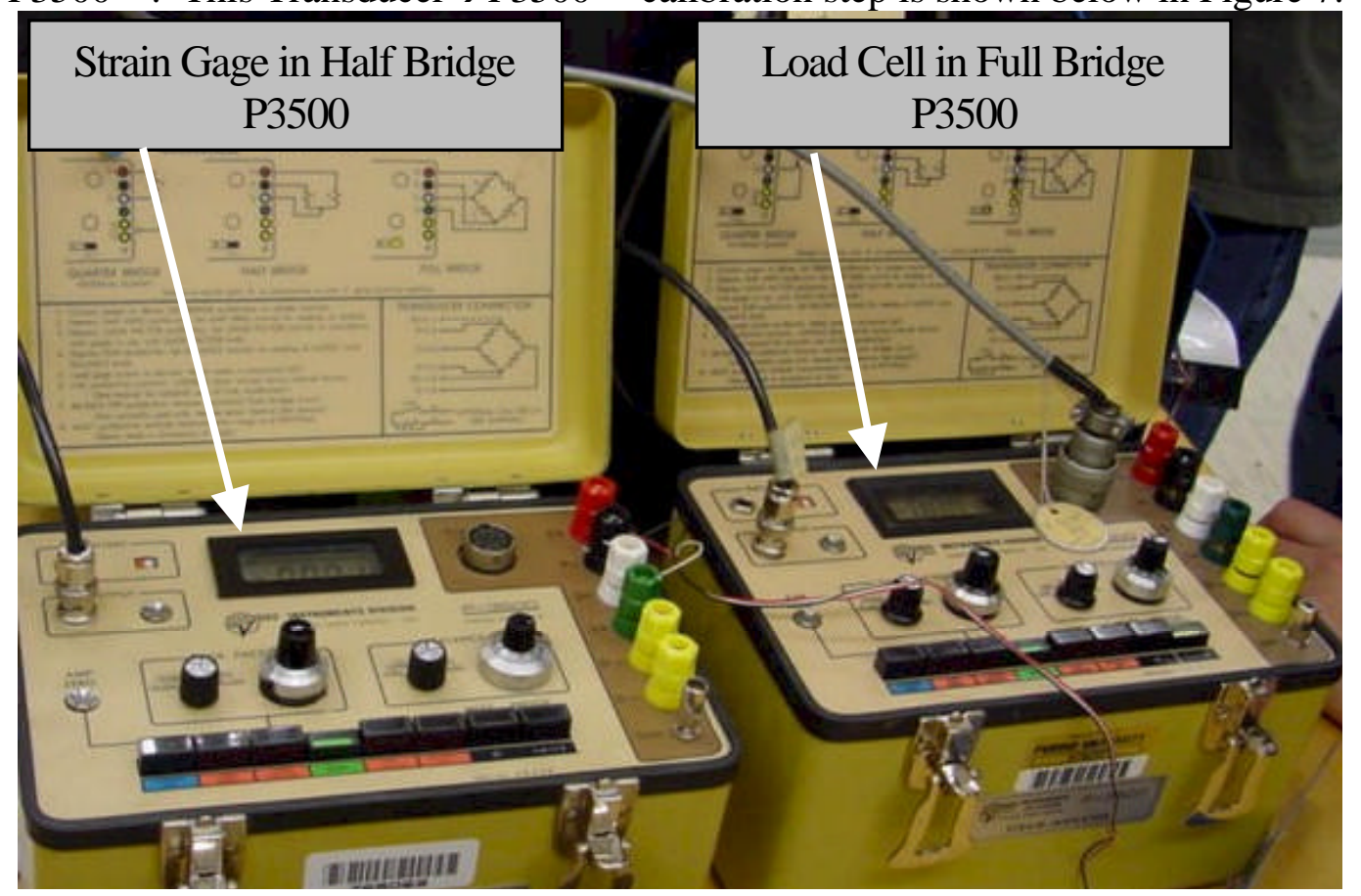

Figure 7: Transducer $\rightarrow \mathrm{P3500}^{\mathrm{TM}}$ calibration step 
After this Transducer $\rightarrow$ P3500 calibration, the calibration of the P3500's to the DAQ is accomplished. The National Instrument ${ }^{\mathrm{TM}}$ signal conditioning unit is connected according to the pinouts specified in the corresponding analog input screen from National Instrument's LabVIEW ${ }^{\mathrm{TM}}$ laboratory automation software. The strain gage P3500 output is differentially connected to the signalconditioning unit with the positive input to pin 57 and the negative input to pin 23 . The load cell P3500 output is also differentially connected to the signal-conditioning unit with the positive input to pin 30 and the negative input to pin 63. Subsequent to the wire hookup, the secondary calibration takes place in a typical manner. The outputs of the P3500's are set to the expected extents and the voltages at the pins are recorded. This step requires care and attention by the student teams and enables a hands-on understanding of the double calibration required for DAQ. These two steps are shown in Figure 8 below.
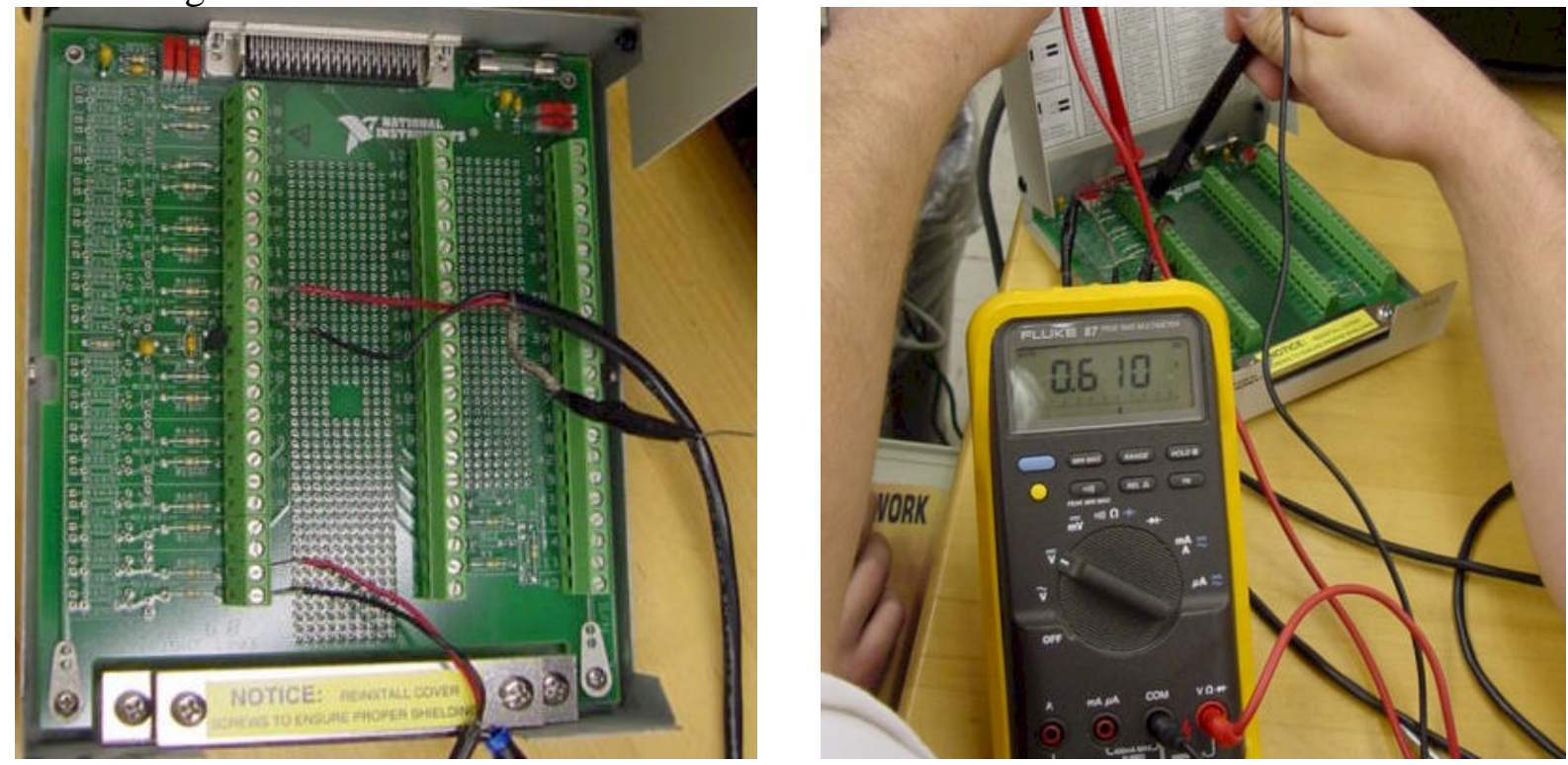

Figure 8: Four point bending secondary connection and calibration using National Instruments ${ }^{\mathrm{TM}}$ signal conditioning unit. Connection is on left and calibration is on right

The secondary connection and calibration is complete when the values are entered into the LabVIEW ${ }^{T M}$ 's Analog Input Configuration screens. Students are encouraged to assure that units match the expected units from the P3500 ${ }^{\mathrm{TM}}$ when mapping the physical quantity to the appropriate sensor. The strain gage Analog Input Configuration screen is shown in Figure 9. 


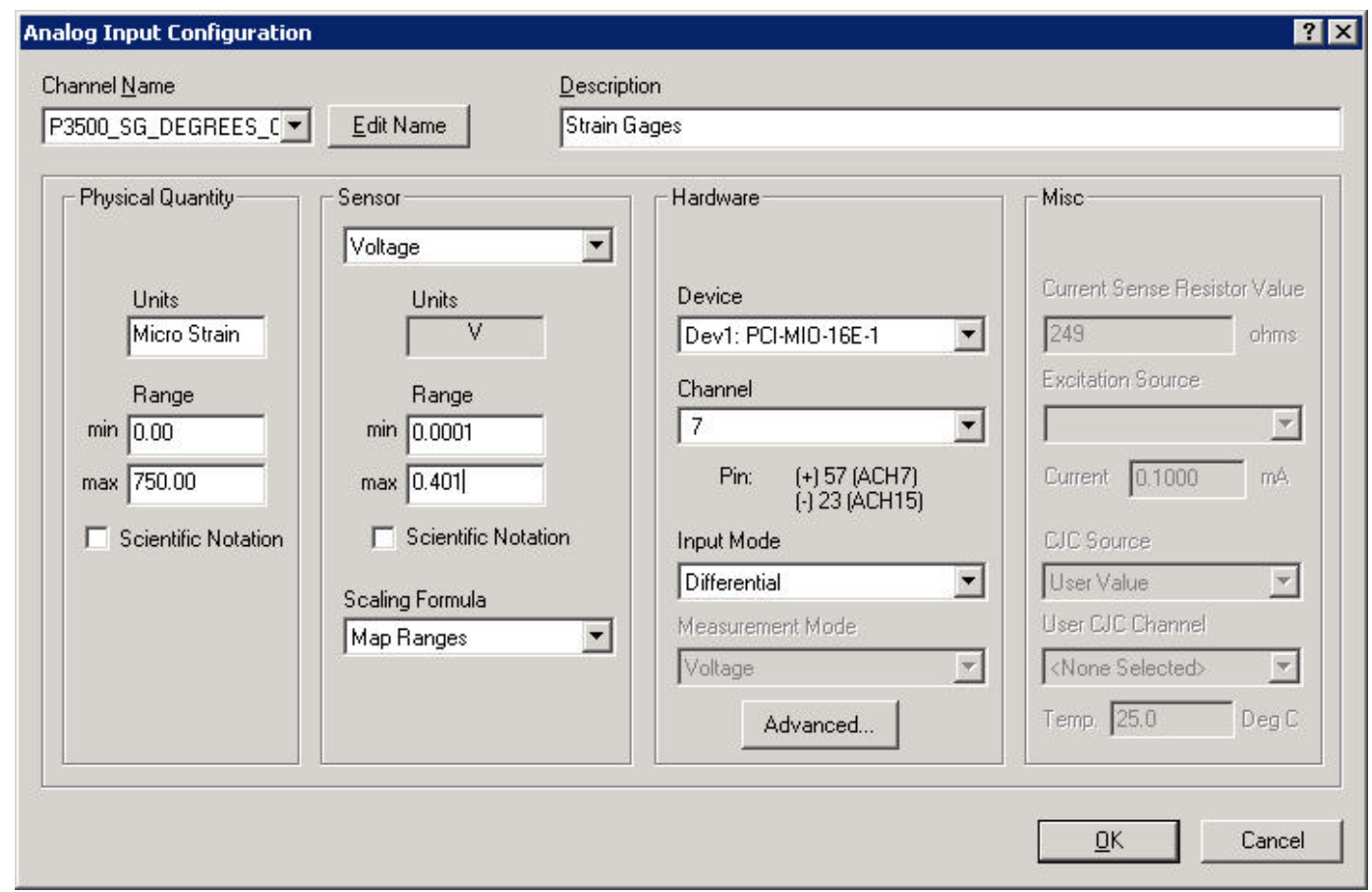

Figure 9: P3500 $^{\mathrm{TM}} \rightarrow$ LabVIEW ${ }^{\mathrm{TM}}$ calibration and setup screen for strain gages.

The strain gage P3500 ${ }^{\mathrm{TM}}$ shown above in Figure 9 has a microstrain range of 0 to 750 uin/in with 0.0001 volts corresponding to the lower value and 0.401 volts corresponding to the upper value. Similarly, the load cell Analog Input Configuration screen shown below in Figure 10 requires a load range of 0 to 1550 pounds corresponding to 0.0026 and 0.420 volts, respectively.

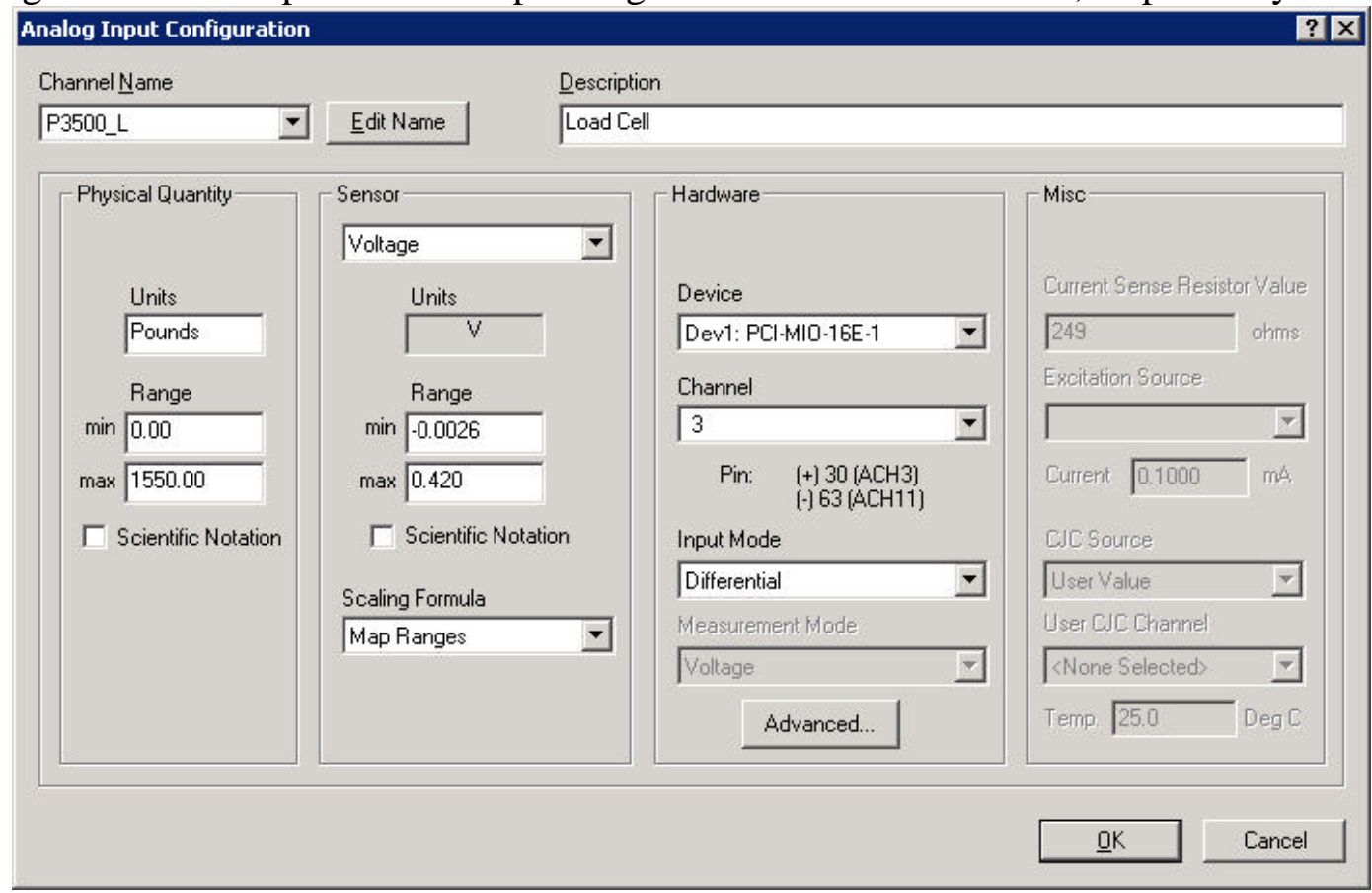

Figure 10: P3500 ${ }^{\mathrm{TM}} \rightarrow$ LabVIEW ${ }^{\mathrm{TM}}$ calibration and setup screen for load cell.

The maximum analytical load expected is 1500 pounds (along with 500 and 1000 pounds) typically enabling student questions. These questions allow discussion to center on attempting to 
provide some additional data points above the expected analytical point as opposed to calibrating only to 1500 pounds.

After calibration, LabVIEW ${ }^{\mathrm{TM}}$ operation is manually correlated to the UTM operation through student communication and action. The signal to start the UTM is given verbally by the LabVIEW team member. While the test is underway, students monitor the load cell load and stop the UTM when the load exceeds $1550 \mathrm{lb}_{\mathrm{f}}$. LabVIEW continues to perform data acquisition until the established number of samples is taken at the established sample rate. On the LabVIEWTM Virtual Instrument (VI), students establish a path to an Excel ${ }^{\mathrm{TM}}$-format file that they desire LabVIEW $^{\text {TM }}$ to write the raw data acquired during the run. In Figure 11 below, the .xls file is specified in the lower right corner of the LabVIEW ${ }^{T M}$ VI. It has been instructive to have the students rename the file for each run to help with subsequent data reduction and analysis.

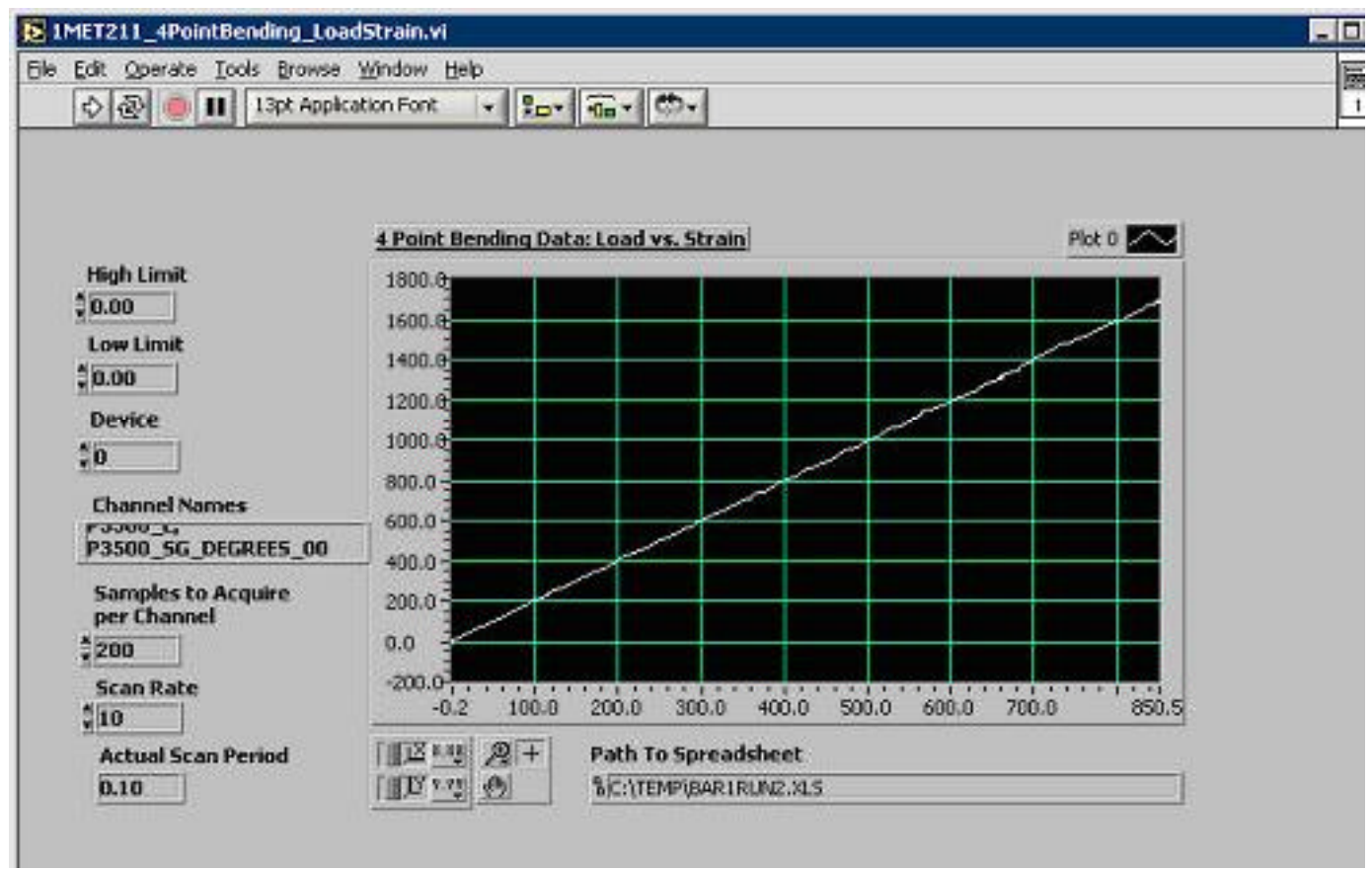

\section{Figure 11: LabVIEW ${ }^{\mathrm{TM}}$ setup and output screen for transducer and MS Excel ${ }^{\mathrm{TM}}$ interfacing for 1" $x 1$ 1 1/26" beam (Bar 1). After run, raw data plot appears in LabVIEWTM.}

Note the slight increase in raw data noise as the beam height increases in Figure 12, which shows

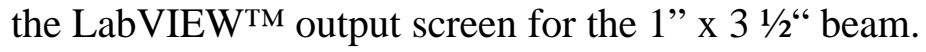




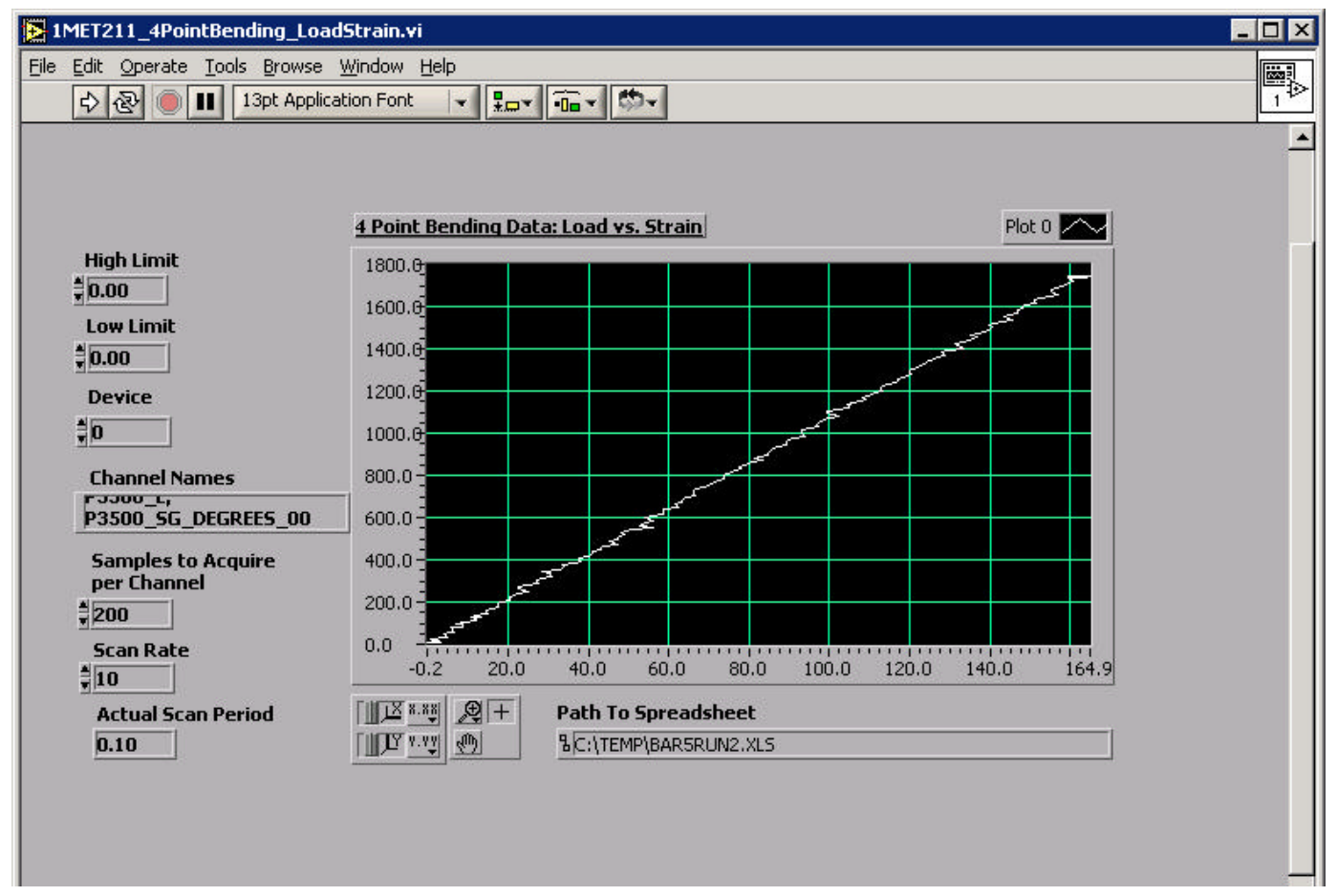

Figure 12: LabVIEW ${ }^{\mathrm{TM}}$ setup and output screen for the 1" $x 3$ 1/26" beam (Bar 5)

The Excel ${ }^{\mathrm{TM}}$ raw data within each file written from LabVIEWTM is in two-column format for the FPB laboratory, with Channel 1 data (e.g. Load) being mapped to the first column of the spreadsheet file and Channel 2 data (e.g. Strain) being mapped to the second column. Students process these individual raw data files in two major ways, either through referencing the cells from a central raw data spreadsheet or cutting-and-pasting the raw data into a central raw data file. A small sample of the raw data in the Excel ${ }^{\mathrm{TM}}$ spreadsheet for the 1 " $\mathrm{x} 3 \mathrm{1} / 2$ " beam is shown in Figure 13 below.

\begin{tabular}{|c|c|c|c|c|c|c|c|c|}
\hline \multicolumn{8}{|c|}{ ® Microsoft Excel - BAR5RUN2 } & \multirow{2}{*}{ 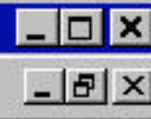 } \\
\hline 图 & ile Edit & Yiew Insert & Format & Tools & Data & Window & $\underline{\text { Help }}$ & \\
\hline & A & $\mathrm{B}$ & $\mathrm{C}$ & & $\bar{D}$ & $E$ & $\mathrm{~F}$ & $\overline{1}$ \\
\hline 1 & 6.850 & 2.553 & & & & & & \\
\hline 2 & 9.536 & 3.238 & & & & & & \\
\hline 3 & 8.641 & -0.187 & & & & & & 卌 \\
\hline 4 & 8.641 & 1.640 & & & & & & \\
\hline 5 & 13.118 & 1.411 & & & & & & \\
\hline 6 & 12.223 & 0.955 & & & & & & \\
\hline 7 & 7.745 & 1.411 & & & & & & \\
\hline 8 & 12.223 & 2.325 & & & & & & \\
\hline 9 & 16.700 & 2.782 & & & & & & \\
\hline 10 & 22.968 & 2.325 & & & & & & \\
\hline 11 & 23.863 & 0.726 & & & & & & \\
\hline 12 & 33.713 & 4.837 & & & & & & \\
\hline 13 & 36.400 & 4.380 & & & & & & \\
\hline 14 & 48.936 & 3.924 & & & & & & \\
\hline
\end{tabular}

Figure 13: LabVIEW $^{\mathrm{TM}} \rightarrow$ Excel $^{\mathrm{TM}}$ raw data for the 1" $x 31 \frac{1}{2^{6 /}}$ beam (Bar 5) 
Given the electronic form of the data, the students are asked to analyze multiple load points (e.g. $500 \mathrm{lb}_{\mathrm{f}}, 1000 \mathrm{lb}_{\mathrm{f}}$, and $1500 \mathrm{lb}_{\mathrm{f}}$ instead of the previous $500 \mathrm{lb}_{\mathrm{f}}$. This extra analysis is performed with little extra time by the student and provides a good opportunity for learning about linearity and hysteresis. After the raw data is aligned in the spreadsheet for each of the two runs, a chart is created allowing a best fit line to be inserted using regression through the raw data points. The equations of these curves provide the means to determine strain levels for the given three load levels of $500 \mathrm{lb}_{\mathrm{f}}, 1000 \mathrm{lb}_{\mathrm{f}}$, and $1500 \mathrm{lb}_{\mathrm{f}}$. Figure 14 below shows some typical values for the strains interpolated from the regression lines. Figure 15 below shows a log-log chart of measured strain versus beam height. This log-log chart can be used to derive the power relationship (based on $\left.\mathrm{y}(\mathrm{x})=\mathrm{Cx}^{\mathrm{M}}\right)$ between strain and beam height as shown in Equation 3.

$$
\varepsilon=\mathrm{C} * \mathrm{~h}^{-\mathrm{M}}
$$

Comparing the coefficients of the empirical and theoretical power equations shows very close correlation with an average $\mathrm{M}_{\text {empirical }}=-1.99$ and $\mathrm{M}_{\text {theoretical }}=-2.00$.

\begin{tabular}{|l|c|r|r|r|}
\hline Bar \# & \multicolumn{3}{|l|}{ Size } & \multicolumn{3}{|c|}{ Strain [microinch/inch] @ Load [lbf]: } \\
\hline & & $\mathbf{5 0 0}$ lbf & $\mathbf{1 0 0 0 ~ l b f}$ & $\mathbf{1 5 0 0 ~ l b f ~}$ \\
\hline Bar 1 & $1 "$ x 1 1/2" & 254 & 511 & 762 \\
\hline Bar 2 & $1 "$ x 2" & 146 & 297 & 441 \\
\hline Bar 3 & $1 "$ x 2 1/2" & 95.4 & 190 & 281 \\
\hline Bar 4 & $1 "$ x 3" & 66.8 & 131 & 196 \\
\hline Bar 5 & $1 "$ x 3 1/2" & 48.3 & 93.9 & 140 \\
\hline
\end{tabular}

Figure 14: Strains obtained from the regression line equations

For this experiment, the experimental error, based on the exponent $\mathrm{M}$, was less than $2.7 \%$ at the $500 \mathrm{lb}_{\mathrm{f}}$ load and dropped to less than $0.5 \%$ at the $1000 \mathrm{lb}_{\mathrm{f}}$ and $1500 \mathrm{lb}_{\mathrm{f}}$ loads.

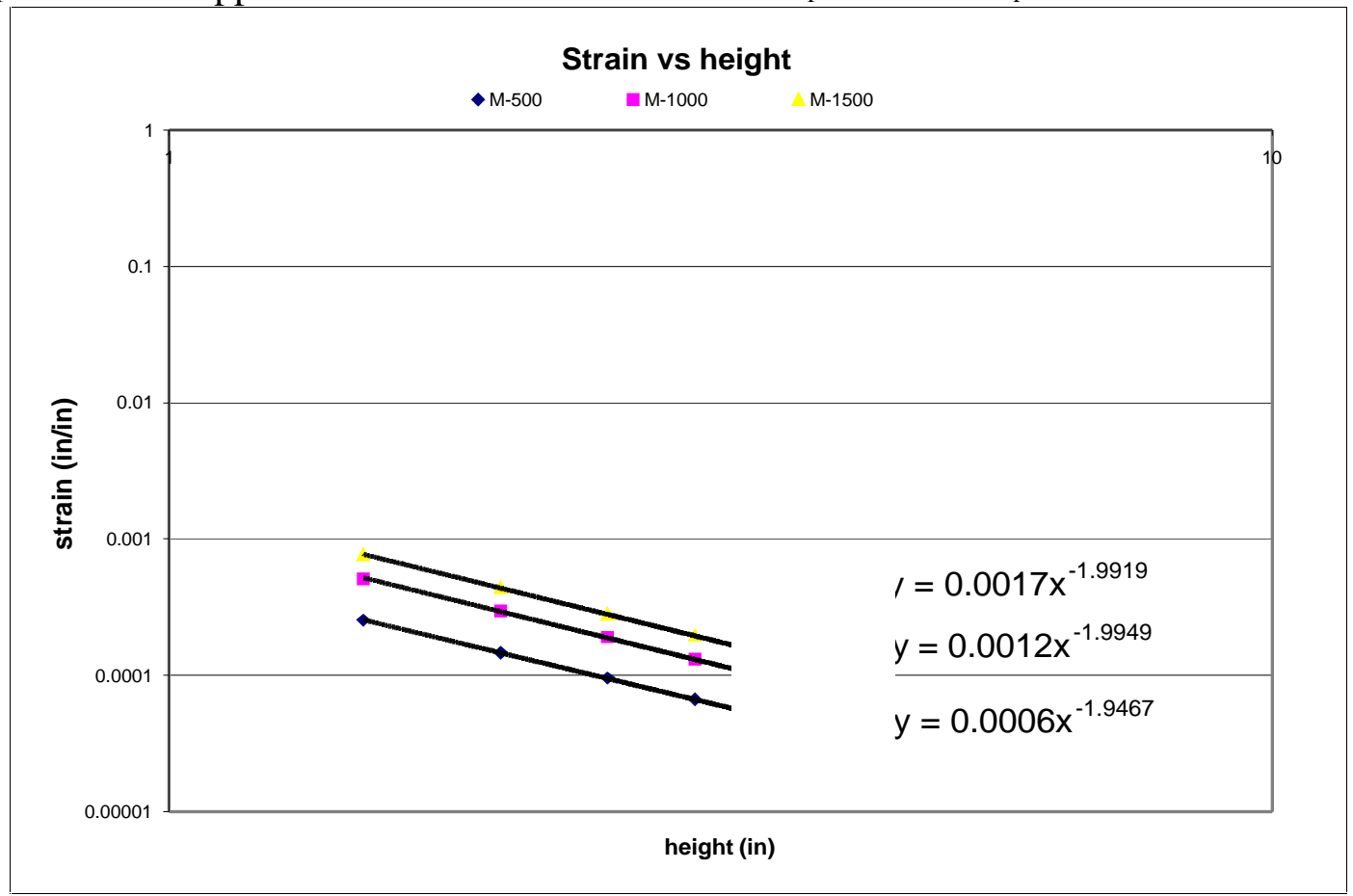

Figure 15: Excel $^{\mathrm{TM}}$ chart of actual strain versus beam height at 500, 1000, and $1500 \mathrm{lb}_{\mathrm{f}}$ 


\section{Conclusions:}

The upgrades to the four point bending laboratory have succeeded in providing mechanical technology students a modern, DAQ-based learning experience. This upgrade has retained and enhanced the FPB laboratory's traditional emphasis on understanding of concepts through handson learning. Students gain through data collection methods that model current industry practice, benefit from the added data collection and analysis with minimal additional effort, and are better prepared for future courses in the areas of instrumentation and experimental mechanics through their exposure to DAQ.

\section{Bibliography:}

1. Denton, N.L., Magill, M.A., Hillsman, V.S., Roach, H.R., Thelen, R.K. (2000).Strength of Materials Laboratory Manual. West Lafayette, IN: Learning Systems Incorporated.

2. Shigley, J.E, Mischke, C.R., (1989), Mechanical Engineering Design $\left(6^{\text {th }}\right.$ ed.), N.Y., New York: McGraw-Hill.

3. Mott, R.L. (2001). Applied Strength of Materials ( $4^{\text {th }}$ ed.). Englewood Cliffs, NJ: Prentice-Hall.

4. American Society for Testing of Materials. (2001).D6272-00 Standard Test Method for Flexural Properties of Unreinforced and Reinforced Plastics and Electrical Insulating Materials by Four-Point Bending, West Conshohocken, Pennsylvania: American Society of Testing and Materials.

5. National Instruments Incorporated website (January, 2002), http://www.ni.com.

6. Vishay Measurement Group website (January, 2002), http://www.measurementsgroup.com

\section{Biography:}

WILLIAM K. SZAROLETTA, P.E.

Professor Szaroletta is an assistant professor of mechanical engineering technology at Purdue University. A member of ASEE, he has 18 years industry experience in engineering and project management positions, with 12 awarded patents. He has 6 years university teaching experience, where his current applied research interests are rapid product design engineering, experimental mechanics laboratory automation, and optimization utilizing genetic algorithms.

\section{NANCY DENTON, P.E., CVS II}

Nancy L. Denton is an associate professor of mechanical engineering technology at Purdue University. She regularly teaches courses in design documentation, solid mechanics, controls, and machinery diagnostics. She has chaired the Women in Engineering and Mechanics Divisions of ASEE, is Past Editor of the Journal of Engineering Technology currently serves as PIC III Chair, and is a member of ASME and the Vibration Institute. 